\title{
A amamentação como fator de proteção para a alergia à proteína do leite de vaca na infância: o que dizem as evidências científicas?
}

The breastfeeding as a protection factor to allergy to cow milk protein in childhood: what the scientific evidences say?

La lactancia como factor de protección para la alergia a la proteína de la leche de vaca em la infância: ¿qué dicen las evidencias científicas?

Samylla Maira Costa Siqueira ${ }^{1 *}$, Climene Laura de Camargo ${ }^{1}$, Josely Bruce dos Santos ${ }^{1}$, Waltamy Mota da Silva Junior ${ }^{2}$, Claudenice Ferreira dos Santos², Danielle de Andrade Canavarro².

\section{RESUMO}

Objetivo: Investigar o que dizem as evidências científicas sobre a amamentação como fator de proteção para a alergia à proteína do leite de vaca (APLV) na infância. Métodos: Revisão integrativa da literatura. Foram selecionados 7 artigos, consultados a partir dos Descritores em Ciências da Saúde "fatores de risco, alergia e leite de vaca", os quais foram combinados pelo uso do operador Booleano AND. Os critérios de inclusão foram publicações dos últimos 5 anos em inglês, português e espanhol. Foram excluídos os trabalhos repetidos e aqueles que não respondiam à pergunta de pesquisa proposta. Resultados: Todos os artigos consultados apontaram para a amamentação como uma forma de prevenção de alergias, caracterizando o leite materno como o alimento adequado na prevenção de APLV. Diante disso, o tempo de manutenção do aleitamento materno exclusivo foi caracterizado como estatisticamente significativo para a ocorrência de APLV e o leite materno como fator de proteção contra alergias, dentre as quais a APLV. Considerações finais: Considerando-se que a APLV é a alergia mais comum na infância, com diversas manifestações que comprometem a saúde e a qualidade de vida da criança, é importante estimular a prática do aleitamento materno como uma forma de promover a saúde da criança.

Palavras-Chave: Saúde da criança, Alergia, Enfermagem.

\section{ABSTRACT}

Objective: To investigate what say the scientific evidences about the breastfeeding as a protection factor to cow's milk protein allergy (CMPA) in childhood. Methods: Integrative literature review. Were selected 7 articles, consulted using the Health Sciences Descriptors "risk factors, allergy and breast-milk substitutes", which were combined using the Boolean operator $A N D$. The inclusion criteria were publications the past 5 years in English, Portuguese and Spanish. Were excluded the repeated articles and those with didn't answer the research question. Results: All the articles consulted pointed to breastfeeding as a way to prevent allergies, characterizing the breast milk as the most adequate aliment in the CMPA prevention. In light of this, maintenance time of exclusive breastfeeding was characterized as statistically significant to occurrence of CMPA and the breast milk as protection factor against allergies, among which the CMPA. Final considerations: Considering that the CMPA is the most common allergy in childhood, with a lot of manifestations that compromise the health and the life quality of child, it's necessary to foster this practice as form to promote the child health.

Key words: Child health, Allergy, Nursing.

\footnotetext{
1 Universidade Federal da Bahia (UFBA), Salvador - BA. *E-mail: smcsiqueira@hotmail.com

${ }^{2}$ Centro Universitário Jorge Amado (UNIJORGE), Salvador - BA.
} 


\section{RESUMEN}

Objetivo: Investigar lo que dicen las evidencias científicas sobre la lactancia como factor de protección para la alergia a la proteína de la leche de vaca em la infancia. Métodos: Revisión integrativa de la literatura. Fueron seleccionados 7 artículos, consultados a partir de los Descriptores em Ciencias de la Salud "factores de riesgo, alergia y substitutos de laleche humana", los cuales fueron combinados con el uso del operador booleano $A N D$. Los criterios para su inclusión fueron publicaciones delos últimos 5 años, en inglés, portugués y español. Fueron excluidos los trabajos repetidos y aquellos que no respondían a la pregunta de investigación. Resultados: Todos los artículos consultados apuntaron para el amamantamiento como una forma de prevención de alergias, caracterizando la lactancia materna como el alimento adecuado en la prevención de alergia a la proteína de la leche de vaca. Frente a esto, el tiempo de mantenimiento de la lactancia materna exclusiva fue caracterizado como estadísticamente significativo para la ocurrencia de alergia a la proteína de la leche de vaca y la leche materna como factor de protección contra alergias, entre los cuales está la alergia a la proteína de la leche de vaca. Consideraciones finales: Considerándose que la alergia a la proteína de la leche de vaca es la alergia más común em la infancia con diversas manifestaciones que comprometen la salud y la calidad de vida del niño, es necesario el fomento de esta práctica como una forma de promover la salud de los niños.

Palabras clave: Salud del niño, Alergia, Enfermería.

\section{INTRODUÇÃO}

A microbiota intestinal do recém-nascido (RN) sofre influências de uma complexa variedade de fatores fisiológicos, culturais e ambientais, que se relacionam principalmente ao período antenatal como tipo de parto, idade gestacional, ambiente familiar, estilo de vida da família, dieta materna e do RN, nível de estresse materno, doenças maternas e neonatais, e uso de antibióticos durante a gravidez ou no período neonatal. Estes e outros fatores fazem com que imediatamente após o nascimento sejam introduzidas no corpo do neonato bactérias que começam a estabelecer no intestino da criança um ecossistema microbiano (FERNANDES TF, 2018).

Esse ecossistema microbiano, composto principalmente pelas bifidobactérias - as bactérias mais prevalentes na microbiota infantil - inibem o crescimento de bactérias caracterizadas como nocivas, estimulam as funções imunológicas, auxiliam na digestão e/ou absorção dos ingredientes e minerais dos alimentos, e contribuem para a síntese de vitaminas (FERNANDES TF, 2018), o que explica a fundamentalidade do leite materno na dieta de lactentes, tanto no contexto da manutenção do adequado funcionamento do trato gastrintestinal como no que concerne à proteção exercida pelo sistema imunológico da criança.

Classificam-se como intolerância ou alergia alimentar as reações adversas a alimentos, sendo a primeira causada por desordens metabólicas - como deficiência de lactase - e a segunda relacionada a reações imunologicamente mediadas, podendo ser IgE mediada ou não $\operatorname{lgE}$ mediada. Embora qualquer alimento possa desencadear a alergia alimentar, destaca-se o leite como um dos mais frequentemente envolvidos nos processos alérgicos (ROCHA FILHO W, et al., 2014).

A alergia às proteínas do leite de vaca (APLV), definida como uma reação adversa do sistema imune aos antígenos presentes neste tipo de alimento Saarinen KM, et al. (1999), é considerada como a alergia mais frequente em pediatria Petriz NA, et al. (2017), sendo um diagnóstico comum em bebês (SÁNCHEZVALVERDE F, et al., 2019). De acordo com Rocha Filho W, et al. (2014), trata-se de uma reação que pode ser mediada por anticorpos, por células ou por ambos, com participação dos quatro tipos básicos de reações imunológicas de Gell e Coombs: tipo I (IgE-mediada), tipo II (reação citotóxica), tipo III (por imunocomplexos) e tipo IV (mediada por células).

Ao tratarem das manifestações clínicas da APLV, Ferreira S, et al. (2014) apontam para a inexistência de sinais ou sintomas patognomônicos, sendo seu espectro variável, com presença de distúrbios gastrointestinais (ROCHA FILHO W, et al., 2014; ERRÁZURIZ G, et al., 2016; PETRIZ NA, et al., 2017;

REAS/EJCH | Vol.Sup.n.49 | e485 | DOI: https://doi.org/10.25248/reas.e485.2020 Página 2 de 9 
PENSABENE L, et al., 2018; TOPAL E, et al., 2019), cutâneos (ROCHA FILHO W, et al., 2014; PETRIZ NA, et al., 2017; TOPAL E, et al., 2019), respiratórios, circulatórios (ROCHA FILHO W, et al., 2014; TOPAL E, et al., 2019) e anafilaxia (ROCHA FILHO W, et al., 2014) e, apesar de se tratar de um problema com bom prognóstico (TOPAL E, et al., 2019), Muraro A, et al. (2014) referem que a alergia alimentar pode ter efeitos significativos na morbidade e na qualidade de vida, além de acarretar diversos ônus em termos de consultas e tratamentos médicos. Diante disso, recomenda-se dieta de restrição, com necessidade de exclusão do alimento até melhora ou desaparecimento dos sintomas relacionados ao problema (PENSABENE $L$, et al., 2018; SÁNCHEZ-VALVERDE F, et al., 2019).

Topal E, et al. (2019) referem que os parâmetros clínicos para duração e magnitude da APLV ainda não são totalmente conhecidos na pediatria. Sabe-se, contudo, que a tolerância se desenvolve ao longo do tempo. Quanto aos fatores que podem se relacionar à ocorrência da APLV, alguns estudos apontam fatores intrínsecos, como a hereditariedade (SARDECKA I, et al., 2018) e fatores extrínsecos como a interrupção precoce do aleitamento materno (SARDECKA I, et al., 2018; LUZ E SILVA et al., 2019), revelando ser a amamentação fator essencial na proteção à saúde da criança e prevenção de doenças como a APLV (LUZ E SILVA et al., 2019). Cabe destacar que o aleitamento materno exclusivo (AME) até os seis meses de vida é tratado pelo Consenso Brasileiro sobre Alergia Alimentar (SOLÉ D, et al., 2018) como a única medida que pode diminuir a chance de ocorrência das alergias alimentares.

De acordo com Fernandes TF (2018), a microbiota intestinal de bebês alimentados exclusivamente com leite materno é diferente daqueles alimentados com aleitamento artificial. O leite materno é rico em fibras prebióticas do tipo oligossacarídeos que influenciam na composição da microbiota intestinal, além de ser rico também em bactérias, principalmente aquelas dos gêneros Lactobacillus, Staphylococcus, Enterococcus e Bifidobacterium. Os oligossacarídeos do leite materno compõem um grupo de carboidratos com mais de mil diferentes estruturas moleculares que promovem o crescimento específico de bactérias, particularmente as bifidobactérias, caracterizadas como positivas para o trato gastrintestinal da criança.

Apesar de ter havido um aumento significativo nas taxas de aleitamento materno desde a década de 1970, conforme revelado por Pérez-Escamilla $R$, et al. (2012), estas ainda se encontram aquém daquelas caracterizadas como adequadas, revelando a necessidade de incentivo às políticas públicas para promoção do aleitamento materno (LUZ E SILVA et al., 2019).

Frente a tais achados, se faz relevante compreender o que dizem as evidências científicas sobre a amamentação como fator de proteção da APLV na infância, uma vez que tal conhecimento pode contribuir no desenvolvimento de estratégias preventivas para o problema e culminar em ações que fortaleçam a prática do aleitamento materno, favorecendo a redução da prevalência de alergia alimentar entre crianças, especialmente ao se considerar que este tipo de alergia, conforme referido por Oliveira ARV, et al. (2018), tem suas taxas de prevalência ascendentes nos últimos anos e pode ter como desfecho a ocorrência de anafilaxia, caracterizada como a principal causa de anafilaxia tratada em serviços de emergência nos Estados, Unidos, especialmente entre os indivíduos mais jovens (SOLÉ D, et al., 2018). Desta forma, o objetivo deste estudo é investigar o que dizem as evidências científicas sobre a amamentação como fator de proteção para a APLV na infância.

\section{MÉTODOS}

Revisão integrativa da literatura, de abordagem qualitativa, descritiva e exploratória, realizada em março de 2020 e norteada pela seguinte questão de pesquisa: o que dizem as evidências científicas sobre a amamentação como fator de proteção para a APLV na infância?

A busca ocorreu na Biblioteca Virtual em Saúde (BVS) pelo uso dos Descritores em Ciências da Saúde (DeCS) "fatores de risco, alergia, leite de vaca", combinados pelo operador booleano AND. A associação dos descritores permitiu identificar 68 trabalhos, os quais foram filtrados pelos seguintes critérios de inclusão: texto completo, em inglês, português e espanhol nos últimos 5 anos. Os critérios de exclusão foram trabalhos duplicados e aqueles que não respondiam à questão de pesquisa apresentada neste estudo. 
Por não se tratar de pesquisa aplicada, não foi necessária submissão e aprovação por Comitê de Ética em Pesquisa. Refere-se, contudo, que todos os autores consultados foram devidamente citados e referenciados, de forma a respeitar as recomendações éticas contidas na Lei número 9.610, de 19 de fevereiro de 1998, que regulamenta os direitos autorais (BRASIL, 1998).

\section{RESULTADOS}

Dos 68 trabalhos identificados pela combinação dos descritores no banco de dados, após aplicar os critérios de inclusão, ficaram 22 artigos. A partir da análise destes trabalhos, 15 foram excluídos: 2 porque estavam repetidos e 13 porque não respondiam à pergunta de pesquisa. Diante disso, foram selecionados 7 artigos, apresentados no Quadro 1.

Quadro 1 - Caracterização dos artigos selecionados. Salvador-BA, Brasil, 2020.

\begin{tabular}{|c|c|c|c|c|}
\hline ID & Autoria/Ano & Periódico & $\begin{array}{c}\text { Tipo de } \\
\text { Estudo/Local }\end{array}$ & Resultados \\
\hline 1 & $\begin{array}{l}\text { Toro } \\
\text { Monjaraz } \\
\text { EM, et al., } \\
2015\end{array}$ & $\begin{array}{l}\text { Rev } \\
\text { Gastroenterol } \\
\text { Mex }\end{array}$ & $\begin{array}{l}\text { Caso- } \\
\text { controle/México }\end{array}$ & $\begin{array}{l}\text { A duração da amamentação em meses foi } \\
\text { um dos fatores apontados como } \\
\text { estatisticamente significativos }(P<0,001) \\
\text { para a ocorrência de APLV. }\end{array}$ \\
\hline 2 & $\begin{array}{l}\text { Errázuriz G, } \\
\text { et al., } 2016\end{array}$ & Rev Chil Pediatr & Retrospectivo/Chile & $\begin{array}{l}\text { Menos de } 50 \% \text { das crianças com APLV } \\
\text { foram amamentadas exclusivamente ao } \\
\text { seio por pelo menos } 6 \text { meses. }\end{array}$ \\
\hline 3 & $\begin{array}{l}\text { Vandenplas } \\
\mathrm{Y}, 2017\end{array}$ & Nutrients & Revisão/Bélgica & $\begin{array}{l}\text { A APLV é muito menos frequente em } \\
\text { bebês amamentados, devendo ser a } \\
\text { amamentação estimulada. Diante disso, o } \\
\text { leite materno é o melhor alimento para os } \\
\text { bebês. Na ausência do aleitamento ao } \\
\text { seio, nos casos de APLV, devem ser } \\
\text { considerados os hidrolisados extensos à } \\
\text { base de leite de vaca, as fórmulas de } \\
\text { aminoácidos (reservadas para os casos } \\
\text { mais graves) e os hidrolisados de arroz e } \\
\text { fórmula infantil de soja (opções de } \\
\text { segunda escolha). }\end{array}$ \\
\hline 4 & $\begin{array}{l}\text { Sardecka I, } \\
\text { et al., } 2018\end{array}$ & $\begin{array}{l}\text { Allergy Asthma } \\
\text { Proc }\end{array}$ & $\begin{array}{l}\text { Caso- } \\
\text { controle/Polônia }\end{array}$ & $\begin{array}{l}\text { As crianças do grupo de estudo foram } \\
\text { amamentadas por um tempo } \\
\text { significativamente menor do que as } \\
\text { crianças do grupo de controle. }\end{array}$ \\
\hline 5 & $\begin{array}{l}\text { Heine RG, } \\
2018\end{array}$ & Nutr Metab & Revisão/Suíça & $\begin{array}{l}\text { A amamentação continua sendo um pilar } \\
\text { fundamental da prevenção primária de } \\
\text { alergias. }\end{array}$ \\
\hline 6 & $\begin{array}{l}\text { Luz e Silva } \\
\text { AM, et al., } \\
2019\end{array}$ & Enferm. glob & $\begin{array}{l}\text { Revisão integrativa } \\
\text { da literatura/Brasil }\end{array}$ & $\begin{array}{l}\text { O leite materno tem efeito protetor contra } \\
\text { alergias, sendo a introdução precoce de } \\
\text { alimentos diferentes do leite humano um } \\
\text { risco nutricional e imunológico para a } \\
\text { criança, com risco de desenvolvimento da } \\
\text { APLV e outras doenças. }\end{array}$ \\
\hline 7 & $\begin{array}{l}\text { Zhang JY, et } \\
\text { al., } 2020\end{array}$ & $\begin{array}{l}\text { Zhongguo Dang } \\
\text { Dai Er Ke Za Zhi. }\end{array}$ & $\begin{array}{l}\text { Clínico } \\
\text { multicêntrico/China }\end{array}$ & $\begin{array}{l}\text { A amamentação exclusiva foi apontada } \\
\text { como um fator de proteção contra a APLV } \\
\text { (OR }=0,21 \text {, IC } 95 \%: 0,08-0,58, P<0,05) \text {. }\end{array}$ \\
\hline
\end{tabular}

Fonte: Siqueira SMC, et al., 2020. 
Em relação à base de dados da indexação, 1 estava na PubMed, 1 na IBECS e 5 na MEDLINE. Quanto ao país de origem dos estudos, apenas 1 foi realizado no Brasil, tendo sido os demais desenvolvidos no México, Chile, Bélgica, Polônia, Suíça e Chile. Em se tratando do idioma, nenhum dos artigos estava em português, tendo sido 3 deles publicados em espanhol e 4 em inglês. Sobre o tipo de estudo, 4 foram originais e 3 foram do tipo revisão. Na Figura 1 é apresentado o organograma que ilustra a busca dos materiais. No que concerne ao aleitamento materno no contexto da APLV, unanimemente os estudos consultados recomendaram pela manutenção da amamentação como forma de prevenir alergias.

Figura 1 - Organograma da busca dos materiais. Salvador-BA, Brasil, 2020.

Pergunta de pesquisa: o que dizem as evidências cientificas sobre a amamentação como fator de proteção para a APLV na infância?
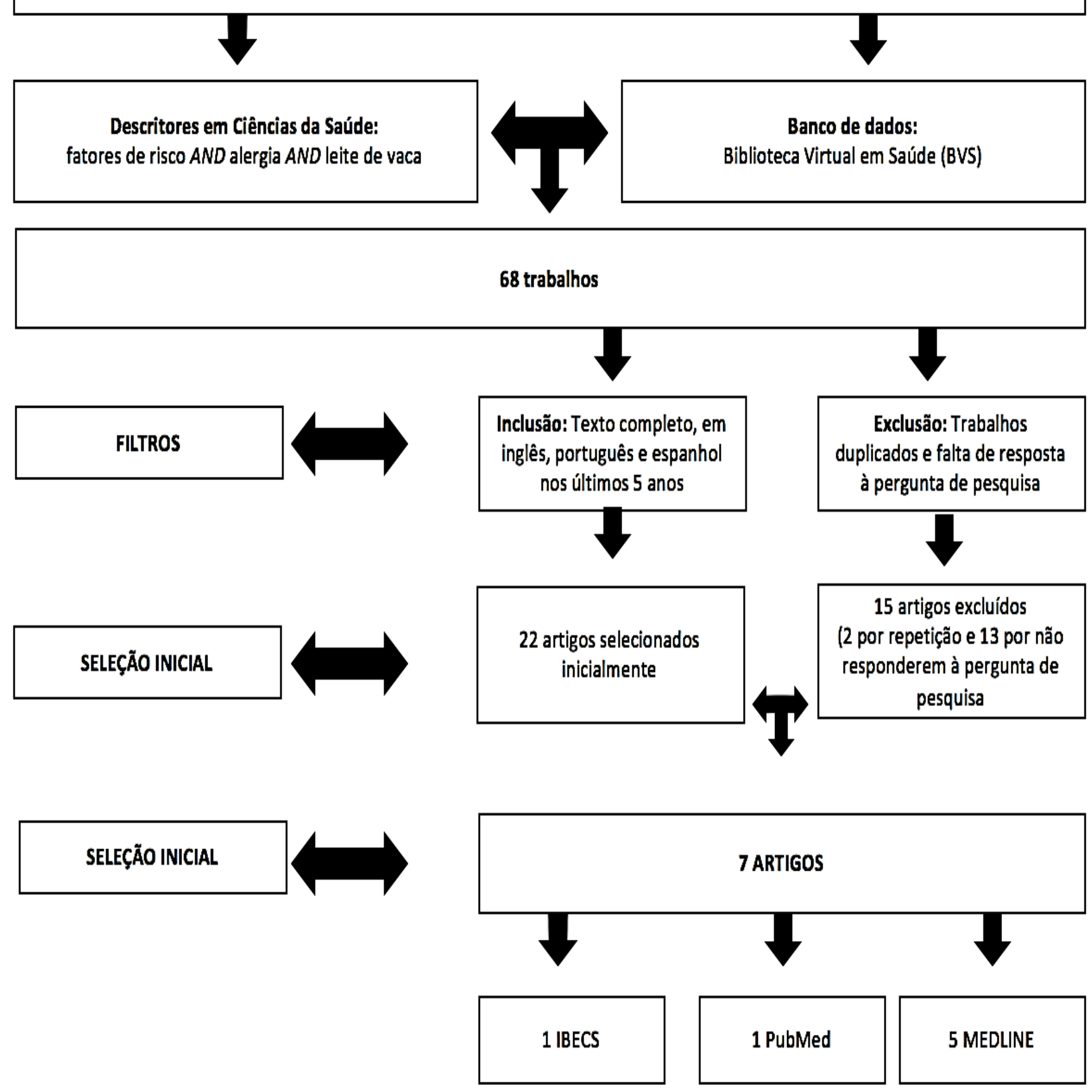

Fonte: Siqueira SMC, et al., 2020. 


\section{DISCUSSÃO}

De acordo com Paixão LA e Castro FFS (2016), o trato gastrintestinal tem funções importantes como nutrição, proteção e imunomodulação, de modo que falhas nestas funções podem culminar no aparecimento de doenças neste sistema, como enterocolite necrosante, atopia e doenças inflamatórias intestinais. Para estas autoras, a microbiota intestinal tem grande influência tanto na saúde como na doença do hospedeiro, sendo necessária à sua estabilização e manutenção desde a infância, evitando ao máximo possível as interferências de fatores internos e externos que causem alterações na microbiota com consequente aparecimento de patologias.

Vieira MC (2017) caracteriza o trato gastrointestinal como um ecossistema complexo em que há uma enorme variedade de bactérias aeróbias e anaeróbias interagindo entre si. Em RN, a colonização das bactérias em um intestino que previamente é estéril se relaciona ao contato com a microbiota materna e do ambiente, sob a influência de diversos fatores. Dentre estes fatores, destaca-se a alimentação, que é apontada como essencial na definição da microbiota intestinal do lactente, a qual, uma vez estabelecida nos primeiros meses de vida, permanece relativamente estável durante a vida do indivíduo, com funções essenciais, dentre as quais as imunológicas (VIEIRA MC, 2017).

Para Vieira MC (2017), tem havido nas últimas décadas um aumento na prevalência das doenças alérgicas, o qual está associado, dentre outros fatores, a mudanças nas condições e hábitos de vida. De acordo com o Consenso Brasileiro sobre Alergia Alimentar (SOLÉ D, et al., 2018), são poucas as evidências que apontam para intervenções capazes de minimizar o aparecimento de doenças alérgicas, sendo o AME a única medida com potencial de diminuir as chances de aparecimento das alergias. Diante disso, é consenso que o AME deve ser mantido até o sexto mês de vida da criança, sendo tal recomendação validada pela Organização Mundial da Saúde (OMS), segundo a qual a única fonte de nutrição recomendada do nascimento até o período de desmame é o leite materno (WHO, 2008).

Vieira MC (2017) defende o aleitamento materno ao referir que o tipo de alimentação é essencial para a definição da microbiota intestinal do lactente, de modo que aqueles que são amamentados com leite materno têm uma microbiota com predominância de bifidobactérias e lactobacilos (80-90\%), enquanto que naqueles em aleitamento artificial essas bactérias correspondem a 40 a $60 \%$ da microbiota, onde se desenvolvem ainda bactérias dos gêneros do clostrídio, estafilococo e bacteróides.

Ao tratar do desmame precoce e da introdução de alimentos sólidos na dieta do lactente, Fernandes TF (2018) ressalta que quando a alimentação complementar é introduzida, aumenta-se a complexidade da microbiota intestinal dos lactentes, que se caracteriza pela diminuição da participação de bifidobactérias apesar de estas ainda manterem-se predominantes - e aumento da diversidade bacteriana, com maior participação daquelas pertencentes aos gêneros Bacteroides e Clostridium.

A partir da revisão de estudos clínicos e experimentais, é possível analisar o papel da microbiota intestinal adquirida no período neonatal no que diz respeito ao desenvolvimento da tolerância oral e de manifestações alérgicas (VIEIRA MC, 2017). No estudo de caso-controle desenvolvido por Toro Monjaraz EM, et al. (2015) e selecionado nesta revisão, os autores identificaram a duração da amamentação em meses como um dos fatores estatisticamente significativos $(P<0,001)$ para a ocorrência de APLV, de modo que as crianças do grupo de estudo foram amamentadas por cerca de 2,2 meses, comparadas às do grupo controle, para as quais a duração foi de 5,9 meses, permitindo aos autores caracterizar o leite materno como o alimento padrão ouro de nutrição infantil por favorecer, além da adequada alimentação, a prevenção de doenças e alergias, uma vez que contém fatores imunológicos.

Ao tratarem da imunologia do leite materno, Soares RCS e Machado JP (2012) referem que o aleitamento materno é uma forma de transferência de imunidade em que estão envolvidas todas as imunoglobulinas, especialmente a IgA, que tem papel fundamental na imunidade. Queiroz VAO, et al. (2013) acrescentam que a lactoferrina humana, um peptídeo natural e a segunda proteína predominante no leite humano, tem atividade antimicrobiana e anti-inflamatória e estimula a proliferação celular e o crescimento da flora bífida, sendo, portanto, capaz de prevenir morbidades, especialmente as gastrintestinais. 
Também no estudo de caso-controle realizado por Sardecka I, et al. (2018), as autoras revelaram que as crianças do grupo de estudo foram amamentadas por um período significativamente menor de tempo do que as do grupo de controle, caracterizando a amamentação como essencial para a prevenção da alergia, particularmente nos estágios iniciais da vida.

A importância da amamentação nos estágios iniciais da vida diz respeito ao fato de este período ser caracterizado como uma fase crítica de imaturidade imunológica do recém-nascido, em especial do sistema imune de mucosas, sendo o leite materno fonte de componentes bioativos para o lactente, especialmente 0 colostro, que é reconhecido pela ciência como o reforço imunológico natural mais potente. Diante disso, o aleitamento materno é capaz de proteger a criança contra infecções por meio dos anticorpos IgA secretores, outros fatores bioativos e fatores anti-inflamatórios (PALMEIRA P e CARNEIRO-SAMPAIO M, 2016), caracterizando-se como o alimento mais adequado para a criança no primeiro ano de vida, dadas as propriedades imunológicas (SILVA DP, et al., 2017).

No trabalho desenvolvido por Zhang JY, et al. (2020), a amamentação exclusiva foi apontada como um fator de proteção contra a APLV. Apesar disso, Melo CS e Gonçalves RM (2014) referem que mesmo havendo diferentes políticas direcionadas à promoção do aleitamento materno, em geral, este não ocorre dentro do tempo necessário e preconizado, sendo substituído pelo aleitamento artificial. Como resposta à baixa prevalência do aleitamento materno e à introdução precoce de leite de vaca e sólidos à dieta dos bebês, Luz e Silva, et al. (2019) destacam uma maior ocorrência de doenças totais e alérgicas, inclusive alimentares. Corroborando tal afirmativa, a pesquisa de Errázuriz G, et al. (2016) teve como um de seus resultados que das crianças com APLV menos de 50\% foram amamentadas exclusivamente ao seio por pelo menos 6 meses.

Acerca da amamentação exclusiva durante o primeiro semestre de vida, Palmeira P e Carneiro-Sampaio M (2016) defendem a necessidade de estimular o aleitamento materno neste período, dado que é uma fase em que a produção própria de IgA secretória é ainda pouco significativa, sendo tal demanda suprida pelo leite materno. Também Luz e Silva, et al. (2019) ratificam que as propriedades de proteção à saúde e prevenção de doenças do leite materno estão fortemente embasadas, ressaltando a importância de manter a lactação exclusiva.

Nas situações em que a criança tem risco de desenvolver alergia alimentar ou que não é amamentada exclusivamente ao seio, a recomendação é que se utilize fórmulas que contenham proteínas extensamente hidrolisadas, pois estas são tidas como hipoalergênicas, pois suas principais proteínas foram modificadas, reduzindo assim a antigenicidade, de modo que pacientes alérgicos à proteína principal são capazes de tolerar a formulação sem apresentar sintomas (ROCHA FILHO W, et al., 2014). Apesar dos benefícios destas fórmulas, Rocha Filho W, et al. (2014) reconhecem que seu custo e a disponibilidade são fatores limitantes em determinadas situações.

De acordo com Solé D, et al. (2018), os lactentes com APLV devem ser mantidos com fórmulas que não contenham a proteína intacta do leite de vaca. Isso pode ser explicado pelo fato de macromoléculas como a caseína e aquelas contidas no soro (alfa-lactoalbumina e beta-lactoglobulina) serem os principais antígenos na APLV, de modo que há necessidade de desintegração da molécula proteica para liberação dos aminoácidos livres, os quais não causam alergia.

Os epítopos, regiões da proteína formadas pela ligação de alguns aminoácidos e as mais alergênicas, são a parte do antígeno que estimula a resposta imunológica. Sua absorção sem que a proteína seja completamente digerida pode ter como resposta o desenvolvimento de tolerância e ausência de reação a elas. Contudo, em indivíduos com predisposição genética a alergias, a absorção do epítopo de uma proteína alergênica terá como resposta a produção de anticorpos lgE específicos e/ou células inflamatórias, acarretando reações alérgicas (APLV, S.D.). Diante disso, destaca-se a importância da não exposição à proteína intacta do leite de vaca por lactentes com APLV (SOLÉ D, et al., 2018).

Na revisão realizada por Heine RG (2018), a amamentação foi apontada como fator de proteção, uma vez que para este autor a amamentação continua sendo um pilar fundamental da prevenção primária de alergias. Naquela conduzida por Vandenplas Y (2017), o autor apontou que a APLV é muito menos frequentes em 
bebês amamentados. Ao tratar do uso de fórmula nos casos de APLV, quando não é possível a amamentação ao seio, evidenciou o uso de hidrolisados extensos como a primeira opção de escolha, os hidrolisados de arroz e fórmulas de soja como opções de segunda escolha e o uso de fórmulas de aminoácidos para casos mais graves. Defendeu, contudo, que o leite materno é o melhor alimento para os bebês e que, portanto, a amamentação deve ser estimulada.

Luz e Silva et al. (2019) revelaram que os estudos consultados em sua revisão apontaram para o efeito protetor do leite materno contra alergias, referindo ser a introdução precoce de alimentos diferentes do leite humano um risco nutricional e imunológico para a criança, além de expor indivíduos nesta fase da vida à APLV e outras doenças. As autoras alertam que além da baixa prevalência do aleitamento materno e da introdução precoce de leite de vaca e sólidos à dieta dos bebês, há também outros fatores que resultam na exposição da criança a doenças totais e alérgicas, como o fato de as mães não seguirem as orientações profissionais acerca do início da introdução alimentar, ressaltando a importância do estreitamento de vínculos entre profissionais de saúde e famílias, com o intuito de estabelecer maior confiança nas orientações sobre a importância do aleitamento materno exclusivo.

A importância do estabelecimento de vínculo entre profissionais de saúde e gestantes foi demonstrada na pesquisa de Silva DD, et al. (2018), na qual foi percebida a ausência de orientações sobre manejo da amamentação, o que fez com que as gestantes buscassem informações na mídia digital e nas redes de apoio. Em direção oposta, o trabalho desenvolvido por Maciel APP, et al. (2013) revelou que as mães participantes de grupos de educação em saúde tinham maior conhecimento sobre o aleitamento materno, além de afirmarem ter oferecido o leite materno exclusivamente durante os seis primeiros meses de vida, permitindo caracterizar a educação em saúde como um aspecto importante na promoção do aleitamento materno.

Tomando por base tais fatos, é importante incentivar o AME até o sexto mês de vida (LUZ E SILVA AM, et al., 2019), pois apesar de algumas evidências não apoiarem a recomendação de atraso de possíveis alérgenos alimentares (GUPTA M e SICHERER SH, 2017) e o adiamento na introdução do leite de vaca e de alimentos sólidos não estar necessariamente relacionado à diminuição no risco de desenvolvimento de alergias alimentares (SOLÉ D, et al., 2018), é sabido que o aleitamento materno tem um grande leque de benefícios, sendo necessário maior incentivo às políticas públicas para promoção desta prática, especialmente em situações patológicas como a APLV (LUZ E SILVA AM, et al., 2019).

\section{CONSIDERAÇÕES FINAIS}

Os estudos selecionados para esta revisão permitiram identificar o aleitamento materno como um fator de proteção contra a APLV. Diante disso, destaca-se a importância de promover ações de estímulos ao aleitamento materno, sendo esta uma forma de contribuir com a saúde da criança.

\section{REFERÊNCIAS}

1. ALERGIA À PROTEÍNA DO LEITE DE VACA (APLV). Entenda alergia. O que é? Disponível em: http://www.alergiaaoleitedevaca.com.br/entenda-alergia. Acesso em: 7 abr. 2020.

2. BRASIL. Lei $n=9.610$, de 19 de fevereiro de 1998. Altera, atualiza e consolida a legislação sobre direitos autorais e dá outras providências. Brasília, 1998. Disponível em: http://www.planalto.gov.br/ccivil_03/leis/l9610.htm. Acesso em: 2 abr. 2020.

3. ERRÁZURIZ G, et al. Características clínicas y manejo de lactantes menores de 1 año con sospecha de alergia a proteína de leche de vaca. Revista Chilena de Pediatría, 2016; 87(6): 449-454.

4. FERNANDES TF. Impactos da microbiota intestinal na saúde do lactente e da criança em curto e longo prazo. Disponível em: http://www.comciencia.br/impactos-da-microbiota-intestinal-na-saude-do-lactente-e-da-criancaem-curto-e-longo-prazo/. Acesso em: 20 abr. 2020.

5. FERREIRA S, et al. Alergia às proteínas do leite de vaca com manifestações gastrointestinais. Revista Nascer e Crescer, 2014; 23(2): 72-79.

6. GUPTA M, SICHERER SH. Timing of food introduction and atopy prevention. Clinics in Dermatology, 2017; 35(4): 398-405.

7. HEINE RG. Food Allergy Prevention and Treatment by Targeted Nutrition. Ann Nutr Metab, 2018; 72(suppl 3): 33-45. 
8. LUZ E SILVA AM, et al. The early food introduction and the risk of allergies: A review of the literature. Enfermería Global, 2019; 59: 499-511.

9. MACIEL APP, et al. Conhecimento de gestantes e lactantes sobre aleitamento materno exclusivo. Revista Brasileira em Promoção da Saúde, 2013; 26(3): 311-317.

10. MELO CS, GONÇALVES RM. Aleitamento materno versus aleitamento artificial. Estudos, 2014; 41 (esp.): 7-14.

11. MURARO A, et al. EAACI Food Allergy and Anaphylaxis Guidelines. Primary prevention of food allergy. Allergy, 2014; 69: 590-601.

12. OLIVEIRA ARV, et al. Alergia alimentar: prevalência através de estudos epidemiológicos. Revista de Ciências da Saúde Nova Esperança, 2018; 16(1): 7-15.

13. PAIXÃO LA, CASTRO FFS. A colonização da microbiota intestinal e sua influência na saúde do hospedeiro. Universitas: Ciências da Saúde, 2016; 14(1): 85-96.

14. PALMEIRA P, CARNEIRO-SAMPAIO M. Immunology of breast milk. Rev Assoc Med Bras, 2016; 62(6):584-593.

15. PENSABENE L, et al. Cow's Milk Protein Allergy in Infancy: A Risk Factor for Functional Gastrointestinal Disorders in Children? Nutrients, 2018; 10(11), 1716.

16. PÉREZ-ESCAMILLA R, et al. Scaling up of breastfeeding promotion programs in low- and middle-income countries: the "breastfeeding gear" model. Adv Nutr Bethesda Md, 2012; 3(6):790-800.

17. PETRIZ NA, et al. Historia natural de la alergia a la leche de vaca mediada por inmunoglobulina $E$ en una población de niños argentinos. Arch Argent Pediatr, 2017; 115(4): 331-335.

18. QUEIROZ VAO, et al. Efeito protetor da lactoferrina humana no trato gastrintestinal. Rev Paul Pediatr, 2013; 31(1):90-5.

19. ROCHA FILHO W, et al. Allergy to cow's milk protein. Rev Med Minas Gerais, 2014; 24(3): 374-380.

20. SAARINEN KM, et al. Suplementary feeding in maternity hospital and the risk of cow's mil allergy: A prospective study of 6209 infants. J Allerg Clin Immunology, 1999; 104(2): 457-461.

21. SÁNCHEZ-VALVERDE F, et al. Factors Associated with the Development of Immune Tolerance in Children with Cow's Milk Allergy. Int Arch Allergy Immunol, 2019; 179:290-296.

22. SARDECKA I, et al. Early risk factors for cow's milk allergy in children in the first year of life. Allergy and Asthma Proceedings, 2018; 39(6): e44-e54.

23. SILVA DD, et al. Promotion of breastfeeding in prenatal care: the discourse of pregnant women and health professionals. Rev Min Enferm, 2018;22:e-1103.

24. SILVA DP, et al. Aleitamento materno: causas e consequências do desmame precoce. Revista Unimontes Científica, 2017; 19(2): 146-157.

25. SOARES RCS, MACHADO JP. Imunidade conferida pelo leite materno. Anais IV SIMPAC - Univiçosa, 2012; 4(1): 205-210.

26. SOLÉ D, et al. Consenso Brasileiro sobre Alergia Alimentar: 2018 - Parte 2 - Diagnóstico, tratamento e prevenção. Documento conjunto elaborado pela Sociedade Brasileira de Pediatria e Associação Brasileira de Alergia e Imunologia. Arq Asma Alerg Imunol, 2018; 2(1): 39-82.

27. TOPAL E, et al. Independent predictive factors for the persistence and tolerance of cow's milk allergy. International Forum of Allergy \& Rhinology, 2019; 9(1): 67-71.

28. TORO MONJARAZ EM, et al. Perinatal factors associated with the development of cow's milk protein allergy. Revista de Gastroenterología de México, 2015; 80:27-31.

29. VANDENPLAS Y. Prevention and Management of Cow's Milk Allergy in Non-Exclusively Breastfed Infants. Nutrients, 2017; 9:731.

30. VIEIRA MC. O Papel da microbiota na alergia. Anais Nestlé - Microbiota: artigos comentados. Disponível em: https://www.nestlenutrition-institute.org/searchresults?indexCatalogue=globalsearch\&searchQuery=microbiota\&wordsMode=AllWords. Acesso em: 20. Abr. 2020.

31. WORLD HEALTH ORGANIZATION (WHO). Indicators for assessing infant and young child feeding practices. Part I: Definition. Geneva: WHO; 2008.

32. ZHANG JY, et al. Risk factors for cow's milk protein allergy in infants: a multicenter survey. Zhongguo Dang Dai Er Ke Za Zhi, 2020; 22(1): 42-46. 